\title{
Blockchain for Good? ${ }^{1}$
}

Beth Kewell, University of Surrey, Surrey, UK.

Richard Adams, University of Surrey, Surrey, UK.

Glenn Parry, University of the West of England, UK.

Explores key areas of Blockchain innovation that appear to represent viable catalysts for achieving global Sustainable Development targets.

Projects and initiatives seeking to extend the reach of Distributed Ledger Technology (DLTs), seem mostly intended for the benefit of for-profit businesses, governments, and consumers.

DLT projects, devised for the public good, could aim, in theory, to fulfil the United Nation's current Sustainable Development Goals (SDG).

Our overview of these initiatives suggests that blockchain technology is being applied in ways that could transform this ambition for good into a practical reality.

Current examples of blockchain deployment are being specified within a value-creation remit that is most likely to benefit for-profit businesses, governments, and consumers (Ng, 2013; Bohme et al., 2015; Swan, 2015; Potts et al., 2016; McWaters et al., 2016; Walport, 2016). Received ideas about what blockchain can and should be used for are based on perceptions that the key role of this technology is to unlock cost savings and secure efficiency gains, whilst also enabling widespread business model transformation (Walport, 2016). Within this scenario, blockchain affordances (Gibson, 1978) are principally seen to 'do good' by resolving longstanding obstacles to profitability and value-capture (Walport, 2016).

The aim of this paper is to consider how blockchain solutions could be used to achieve good outcomes for the sustainable development agenda by, for example, helping to fulfil the UN's Sustainable Development Goals (UN, 2015). Kranzberg's first law of

\footnotetext{
${ }^{1}$ JEL Codes: O38; O39; D20.

Acknowledgements: The authors gratefully acknowledge the support of a

BA/Leverhulme Small Research Grant (SG160335) in the preparation of this work.
} 
technology avers that 'Technology is neither good nor bad; nor is it neutral' (Kranzberg's, 1986, p.545). In doing so, Kranzberg reminds us that innovations are morally and ethically instantiated. To date, research has tended to focus on the technical characteristics, efficiency gains - and profits - to be yielded from blockchain projects and experimental Distributed Ledger Technology (DLTs) and 'permissioned ledgers' being run by private consortia (Ng, 2013; Bohme et al., 2015; Swan, 2015; Potts et al., 2016; McWaters et al., 2016; Walport, 2016). While initially fixed on the commercial and consumer benefits to be drawn from blockchain innovation, attention is beginning to shift toward the appropriation of socially and environmentally beneficial use cases that aim to tackle global challenges such as, for example, financial exclusion (CTPM, 2016).

Drawing on affordance theory, this exploratory paper reflects on innovative applications of blockchain projects that could help deliver socially and environmentally beneficial outcomes by challenging existing business models and providing new opportunities for value creation that also serve a philanthropic purpose (Botsman and Rogers, 2010). We call this 'Blockchain for Good', where 'Good' can be framed in terms of the UN's Sustainable Development Goals (SDG) (UN, 2015). The SDGs provide a vision for governmental, corporate and civic action leading the way towards 'development that meets the needs of the present without compromising the ability of future generations to meet their own needs' (WCED, 1987, para 27). 
The paper proceeds as follows: First, we describe our approach to this exploratory research. Second, we offer a brief overview of the technological characteristics of DLT. Third, we examine the notion that DLTs have unique affordances rendering them appropriate solutions to the SDGs. Consequently, in this article we begin to explore the impact of DLTs on the UN's Sustainable Development Goals which is the contribution of the paper.

\section{Affordances}

The repositioning of blockchain technologies as a device for mobilising good causes, including those positioned at a global level, represents a considerable departure from their original remit as payments reconciliation systems which may be utilised without the need for banks and clearing houses (Ng, 2013; Bohme et al., 2015; Swan, 2015; Welch, 2015; Potts et al., 2016; McWaters et al., 2016; Walport, 2016). The identification of such an important 'change of use' draws attention to a concomitant shift in perceptions of blockchain affordances - that is to say, discernment of what the software can do for sustainable development and environmental protection in parallel with an appreciation of what novel deployment could realise for vulnerable and impoverished communities (Seidel et al. 2013). Key organisations, such as the UN, are actively focused on establishing blockchain's capacity for achieving SDGs in, for example, identity provision and financial inclusion (CTPM, 2016).

Scoping exercises, focused on pinpointing blockchain's potential contribution to the sustainability field may represent a first step towards developing a future 'affordance taxonomy' (Conole and Dyke, 2004) to guide the deployment of blockchain-for-good in 
the third sector and among social enterprises, including those already taking advantage of crowd-funding and other charitable activities made possible by virtual platforms (Choy and Schlagwein, 2016).

Affordances are bestowed upon artefacts - they are the qualities users perceive objects, places, contexts, and constructs, uphold and encompass (Gaver, 1991; Zammuto et al., 2007; Maier and Fadel, 2009; Faraj et al., 2011; Withagen, 2012; Majchrzak and Markus, 2012; Xenakis and Arnellos, 2013; Lankton et al., 2015; Ciavola and Gershenson, 2016; Choy and Schlagwein, 2016; Beynon-Davies and Lederman, 2017). Affordances are bound to expectations of what artefacts can be/can do and thus reputational information (Kewell, 2007) that tells us whether the actions they ought to assist Ciavola and Gershenson (2016, p.252) or facilitate are worthwhile, valuable, risky or unwise (Zammuto et al., 2007). Affordances can therefore be seen to possess an implicit moral imperative (Dierksmeier and Seele, 2016).

Artefacts by themselves have no power; they do nothing (Geels, 2005). Affordance theory suggests that an artefact is fundamentally perceived in terms of its 'action possibilities' (Withagen, 2012, p.521). Drawing on Gibson's (1978) work on the ecology of perception, Pea (1993, p. 51) describes an 'affordance' as the perceived and actual properties of a thing, primarily those functional properties that determine just how the thing could possibly be used. An affordance, then, is what an object or technology offers, provides or furnishes in the context of use: depending on the user, a chair 'affords' sitting or an improvised ladder (Maier and Fadel, 2009); a bicycle 'affords' travel, or exercise or the delivery of health benefits (Conole and Dyke, 2004; 
Maier and Fadel, 2009; Volkoff and Strong, 2013; Lankton et al., 2015; Ciavola and Gershenson, 2016).

Affordance theory subsequently delineates between intended uses built into the design process and consequential affordances, which avail themselves as prototypes are tested, and end-products are evaluated by potential users and consumers leading to the development of 'sequential' and 'nested' affordances (Gaver, 1991, p.4). Original construals of affordance can change markedly by the end of this learning curve (Gaver, 1991). Dual affordances can also emerge over time, once an artefact, prototype or design has acquired up-take (Beynon-Davies and Lederman, 2017). Thus, the recycling movement has also recently shown how the original meaning of an artefact's affordances can be usurped or overturned by, for example, making objects with established or traditional affordance perform tasks for which they were not originally intended. A good illustration of the latter is provided by the current trend in urban cities for 'container living,' whereby redundant sea freight containers are converted into sustainable homes.

A relatively new area of technological affordance theory examines the development of simulated computer technologies and the impact perceptions of what they can do has on human and organizational relations in the 'real world' (Zammuto et al., 2007; Boyd, 2010; Faraj et al., 2011). The affordances of software products can be altered by multiple designers and mass users (Boyd, 2010, p.7). By itself, this capacity rewrites existing conceptions of the interaction between designers, users, artefacts, and the environment in which they are embedded (Zammuto et al., 2007; Faraj et al., 2011; 
Ciavola and Gershenson, 2016). When positioned within social networks (Boyd, 2010), the affordances of simulated technology (such as platforms and blockchains) are percieved to foster new forms of communitarian action and social exchange (Faraj et al., 2011; Choy and Schlagwein, 2016). When considered within an organisational context, these technologies are said to change perceptions of what may be afforded by systems, structures and processes, for example, those illustrated in workflow visualisation software (Beynon-Davies and Lederman, 2017), allowing previously hidden sources of value to become more self-evident (Zammuto et al., 2007; Faraj, et al., 2011; Ciavola and Gershenson, 2016).

The discovery of affordances related to blockchain technology is following patterns identified within inter and intraorganisational contexts. Blockchain is part of a thriving ecosystem, populated, en masse, by designers and users, who are continually improvising new affordances, as they tweak the technology for use in different settings. The advent of usecases for intraorganizational and consortia based blockchain deployment (as DLTs and permissioned ledgers), suggests that it will not be very long before companies begin to perceive blockchains as instruments of change. In what follows, we consider how perceptions of blockchain affordances are likely to change understandings of what can be achieved in the sustainable development field, as an ecosystem that must address mutiple requirements (from disaster relief to microfinance), using extremely complex networks of interactions. Could these interactions be placed on blockchains? Could this placement deliver better outcomes for aspects of society and the environment that are most in need and generate new sources of good? 


\section{Affordances for good}

It is important to consider what we mean by good before addressing these questions. The western philosophical tradition has, for millennia, distinguished between intrinsic and extrinsic good (Smith, 1948) the former, good for its own sake, the latter being derivatives of the former - that is, an extrinsic good is good not for its own sake, but because its enactment leads back to an intrinsic good. The debates about the ontological status of intrinsic and extrinsic good, what constitutes them, the sorts of things that are or have intrinsic or extrinsic good(ness) and how these might be assessed or computed are beyond the scope of this paper. Frankena (1973) provides a comprehensive list of those things which are intrinsically good - as deemed by other authors to be good or rational to desire for their own sakes. Others, for example George Moore (1903), reject the notion of intrinsic good and take a more consequentialist view that things are good when they are perceived to be good, where their consequences are in some sense better than those of alternatives.

There is a substantial literature on ethical issues surrounding ICTs, much of it framed around what constitutes 'better' and how that might be evaluated, including: the impact of technological progress on society (Lee, 2005) and the influence of technology on the development of virtuous interactions (Benkler and Nissenbaum, 2006). Arguing that ICT's beneficial impact can be evaluated by distinguishing between local and systemic levels, the difference between content and process, the implication of Taddeo and Vaccaro's (2011) framing is that an ethical understanding of technologies can be gained 
through an interrogation of how the ways in which they work enable new beneficial actions and outcomes.

In ascribing a DLT initiative as being good, we are undertaking an evaluation. Value is said to be the measure of goodness $(\mathrm{Ng}, 2013)$ and pragmatically we seek to make a judgment of what is good in our case. Our evaluation of DLTs is not based on judgement of an intrinsic or extrinsic goodness. Rather the judgement is based on the decisions made by the people who invent, develop, distribute and use them (Argandoña, 2003) in relation to the consequences of those technologies for the UN's 17 SDGs and 169 targets which, on September 25th, 2015 the 193 Member States of the United Nations unanimously adopted.

DLTs have, in some quarters, received an unfavourable press largely grounded in the observation that the DLT enabled cryptocurrencies - notably Bitcoin -have been associated with illicit and illegal activities such as drug dealing and arms trading (it should be said, a critique that applies equally to cash). Leading financial institutions and banking consortia are currently looking for ways to create their own permissioned or private cryptocurrency ecosystems, (as seen in the example of the ' $r 3$ ' consortium²). Blockchain use cases focus, typically, on mapping the affordances DLTs might convey within largescale finance services (European Central Bank, 2012; Ali et al., 2014; McWaters et al., 2016).With little consensus about the potential impact of DLTs for good or ill, it is clear that the subject requires serious analysis. To focus on a single application or specific usage of the technology is to overlook its possible significance

\footnotetext{
${ }^{2}$ http://r3members.com/
} 
for ethical impacts at a global level. To ensure that the opportunities for ethical action potentially engrained in new technologies such as DLTs may be realized, it is important that the wider significance of the so-called 'Blockchain for Good' (B4G) is understood.

The blockchain first appeared, largely unheralded, in 2008. Attention, instead, was directed toward the application whose existence blockchain technology made possible. The focal application and the first to run on a blockchain was the crypto-currency Bitcoin (Nakamoto, 2008; Lemieux, 2013).

The significance of the underlying DLT is that it enables the digital transfer of value between two unknown entities without the need for a trusted third party. Simply put, DLT allows anyone to transact with anyone anywhere on a P2P basis. DLTs enhance the transparency of information exchanges (including payments and deposits), making trust obligations much easier to discharge between transacting parties. The service of value transfer is normally provided by intermediaries such as banks. DLT reallocates the responsibilities of transfer management to computers and algorithms (Ali et al., 2014; Welch, 2015; McWaters et al., 2016). Because of the way in which the technology is configured to allow P2P digital exchange of value, the blockchain, to many observers, represents a revolutionary and disruptive innovation (Swan, 2015; Zuberi and Levin, 2016).

Fundamentally, a blockchain is a ledger of transactions of digital assets: of who owns what, who transacts what, of what is transacted and when. Transactions are not recorded on a single database but distributed on the computers of the network of users (nodes) of 
the system. No single entity owns or controls the ledger, and so network members can view the recorded transactions. Transactions are recorded and stored in 'blocks,' and each block linked chronologically (hence chain) and cryptographically to those which precede it to create an immutable, tamper-resistant record. All transactions are timestamped to provide a record of when transactions occurred and in what order: this assures against 'double spending' and tampering with previous transaction records (Reber and Feuerstein, 2014). The ledger is 'kept honest' by network consensus, a transaction validation process undertaken by network users, which includes checking that digital signatures are correct through a process known as 'mining': mining is incentivised by reward systems. Once a block is accepted by the network and added to the chain, it cannot be changed: it is a permanent, transparent and immutable record.

Consequently, DLTs may be characterised as globally distributed, P2P, open ledgers of exchange providing an immutable and verifiable record and encrypting the identities of users that is hard to tamper with. Davidson et al. (2016) describe DLTs as a new general purpose technology which are, by definition, highly pervasive and can impact entire economies giving rise to creative destruction (Schumpeter, 1934; Jovanovic and Rousseau, 2005) with the potential to disrupt any centralized system that coordinates valuable information (Wright and De Filippi, 2015).

DLTs represent a fundamental change in the way in which humans can exchange value, and two important implications follow. First, because the technology provides the required trust to give peers the confidence to exchange value directly, the requirement for socially-constructed institutional third-party providers of trust is significantly 
reduced: they become disintermediated. The second implication is that the blockchain presages a new functionality for the internet: it moves from an internet of information to an internet of value (Swan, 2015). It means, that for objects that can be expressed in code, multiple novel application possibilities are opened up, and raises the question, how can blockchain technology that creates immutable, tamper-resistant distributed records of transactions of digital assets be applied in the service of SDGs?

Mattila (2016) points out that the technology stack components of DLTs is diverse and can be configured in a variety of ways, resulting in different DLT architectures, implying the need for design decisions. Blockchains can be categorized as, for example, Permissioned/Permissionless and Specific Purpose Blockchains optimized for the management of assets and General Purpose Blockchains designed to allow users to write their own programmes to be stored on the blockchain and automatically executed in a distributed manner. Notwithstanding these divergences, DLTs share certain characteristics which may be more or less attenuated depending on the context of the application, in particular: the distributed (decentralized) consensus mechanism, immutability, algorithmic trust, resilience against manipulation, and secure information sharing.

Nakamoto's (2008) white paper describes what might be considered to be a pure form of DLT, that is to say a permissionless blockchain encompassing a network of participants that are not known to one another and each of them can access the blockchain with complete freedom to read or write to it, no actor can prevent any other actor from contributing content nor can any actor remove any previously validated 
contribution; and consensus is incentivised through economic mechanisms.

Permissionless Blockchains are therefore highly censorship resistant and can provide an immutable ${ }^{3}$, network-validated global record of transaction histories - right up to the present moment.

On the other hand, anyone ${ }^{4}$ may have a copy of the ledger in a permissioned blockchain, but only certain authorised parties may write to it and the consensus process is determined by the owner(s) of that blockchain, usually carried out by trusted actors in the network (CPTM, 2016). Assuming that chosen actors honestly and disinterestedly validate transactions, then permissioned blockchains can offer certain advantages, in at least two respects: first, they can be designed with specific functionality in mind and, second, alternatives to economically-incentivized validation mechanisms (proof-ofwork) can be incorporated. As a result, permissioned blockchains can be more efficient and faster than unpermissioned versions (CPTM, 2016) but at the cost of reduced security, immutability and censorship-resistance (Mattila, 2016).

A sub-category of the permissioned blockchain is the private blockchain in which only certain authorised users have access to the database, whether for reading or writing, which tend to exist behind some organizational firewall but offer within-group transparency, privacy, and control, for a defined set of users. Whether or not they truly are DLTs continues to be debated, but the permissioned blockchain does have a role in helping deliver the SDG agenda. In the following, we explore some of these further and consider their affordance in terms of the SDGs.

\footnotetext{
${ }^{3}$ Immutable to the extent that that particular blockchain continues to be maintained. It is not clear what happens in the circumstance that a particular blockchain ceases to be maintained by a network. ${ }^{4}$ Anyone, subject to, of course, the nature of the permissions.
} 


\section{Blockchain mining}

In the Bitcoin blockchain, transactions are validated by network members (nodes) in a process known as mining. This distributed, network-member-driven process, performs the function of the centralized trusted third party intermediary model. Network participants compete with each other using computer power (known as proof-of-work) to validate blocks of transactions every 10 minutes or so. The proof-of-work is difficult to produce but easy for other nodes to verify and so transaction validity is established by majority consensus of network members. The miner that first successfully validates a block is rewarded with newly minted Bitcoins ${ }^{5}$.

That network members commit resources to validating transactions, which in turn contributes to the cryptographic security and fraud resilience of the Bitcoin blockchain. The network is configured in such a way that it makes more sense for would-be attackers to participate as miners (greater opportunity for reward at lesser cost), thus increasing the resilience of the blockchain (Doguet, 2013; Fox-Brewster, 2015; Welch, 2015).

However, the computationally intensive method of proof-of-work has been described as costly and wasteful (McWaters et al., 2016). As miners around the world competitively dedicate resources to validate transactions, Aste (2016) estimates about a billion Watts of electricity are consumed globally every second to produce a valid proof of work for Bitcoin. In light of this, alternative validation mechanisms are being investigated, some

\footnotetext{
${ }^{5}$ For more details on mining, see Antonopoulos, A.M. (2014). Mastering Bitcoin: unlocking digital cryptocurrencies, O'Reilly Media, Inc.; Swan, M. (2015). Blockchain: Blueprint for a New Economy, O'Reilly Media, Inc., and: http://www.coindesk.com/information/how-Bitcoin-mining-works/
} 
of which resonate with the SDG agenda but also relax some of the communitarian properties of the proof-of-work approach (such as openness to the whole community).

Dierksmeier and Seele (2016) argue that it should be possible to promote ethical goals in society, by for example, hitching the 'mining' to the creation of ecological or social benefits. Certainly, reducing energy consumption in the process would ameliorate ecological harms and a small number of initiatives have emerged in this area.

SolarCoin $^{6}$, for example, rewards generators of solar energy with new coin; another, GridCoin (Halford, 2014) introduces a novel algorithm based on work done in BOINC (Berkeley Open Infrastructure for Network Computing) projects: miners are incentivized to participate in scientific projects (as in healthcare and space exploration) aiming to provide benefit to humanity. In the CureCoin blockchain, the Bitcoin validation calculations are replaced by (useful) protein folding tasks: mining CureCoin helps science through simulating protein behaviour and providing these data to research scientists.

\section{The internet of value(s)}

The previous section describes how social or ecological benefit can be linked to the production of alt-currencies. This section focuses on how these benefits can be related to currency use. The notion of coloured coins (Bradbury, 2013) is used to denote a small part of a coin with specific attributes which may represent anything from physical assets to a community's values. By moving coloured coins through the network, asset ownership can be securely transferred. Similarly, coins coloured with values, in which

\footnotetext{
${ }^{6}$ https://solarcoin.org/
} 
morals, principles or ethics are embedded in the code, can allow individuals to align their spending closely with their values.

Taghiyeva et al. (2016) describe a proof-of-concept pilot for a blockchain-based Islamic crypto-currency in which transactions and Muslim values, including a blended antiradicalisation agenda, are aligned: a currency with a community's desirable social principles engineered-in. This resonates with Helbing's $(2013,2014)$ concept of Qualified Money where values can be embedded in DLTs. CarbonCoin ${ }^{7}$ claims to be the first digital currency with a conscience, designed to engage the environmentally conscious community. Such possibilities raise important questions about whose values are embedded into a currency and who does the engineering.

In terms of assets, DLTs provide a mechanism both for their registration and transfer. A number of commentators have argued that this may prove a boon in developing or politically unstable economies for the registration of individual's property rights. Where there is a lack of trust in central authorities to maintain uncorrupted registers of assets, such as property title, these may be recorded immutably, transparently, and verifiably on a blockchain. A number of pilots and trial projects are underway: Bitland ${ }^{8}$ use DLT to map land title in Ghana providing a registry of ownership which subsequently facilitates the mobilization of capital as well as a transparent property market. Similar initiatives can be found in Honduras (Alejandro, 2016), Sweden (Rizzo, 2016) and Georgia (Shin, 2016). Progress has been slow and success mixed (ODI, 2016), attesting to the still emergent nature of the technology. Indeed, it is too easy to get carried away

\footnotetext{
${ }^{7} \mathrm{http}: / /$ carboncoin.cc/

${ }^{8} \mathrm{http} / / /$ bitlandglobal.com
} 
by the theoretical potential of DLTs. While a blockchain based registry of assets may be transparent and immutable, for it to be meaningful in terms of economic participation and activity it must exist within a stable infrastructure: armed aggressors, for example, may still unlawfully seize property regardless of whether or not it is recorded on the blockchain. However, the existence and immutability of the record may act as a deterrent against such behaviour.

\section{Supply chains}

Assets can be registered to the blockchain using unique keys. This provides a register of ownership as well as tracking and pattern of ownership over time. Initiatives that have leveraged this affordance include Everledger ${ }^{9}$, a permanent ledger for diamond certification and related transaction history transparently recording ownership history and reducing crime, and Provenance ${ }^{10}$ who provide a system for tracking materials and products in a manner that is public, secure and inclusive. For the SDGs, this means that claims (albeit excluding those blood diamonds or sustainably fished tuna) can be demonstrated to be authentic right through the supply chain, shifting the value system towards origin and provenance (Greenspan, 2015).

DLT applications are also being explored in the energy market both as a system enabling individuals to sell excess solar-generated electricity to each other without going through third parties (such as PowerLedger ${ }^{11}$ and TransActive ${ }^{12}$ ) as well as developing a market infrastructure for carbon trading, an independent ledger of the

\footnotetext{
${ }^{9} \mathrm{http}: / / \mathrm{www}$. everledger.io/

${ }^{10} \mathrm{https}: / /$ www.provenance.org/

${ }^{11} \mathrm{http}: / /$ powerledger.io/

$12 \mathrm{http}: / /$ transactivegrid.net/
} 
permits to emit Earth's allowance of greenhouse gases (Casalotti, 2016). One scenario is that, within a short time, every individual on the planet, for example, be issued with an annual carbon allocation that may be traced via the DLT network.

\section{Innovations in governance}

Within the DLT code substitutes for trust and allows for new types of commerce. Appropriately designed, these can be the building blocks of new forms of economic and social governance that meet the objectives of the SDGs.

Smart contracts are computer protocols that facilitate, verify and enforce the performance of a contract: self-executing code. They are the automation of the performance of contracts which only execute when pre-specified conditions are met, thus removing the need for third party resolution. This is an assured and low-cost mechanism that can offer for Bottom of the Pyramid economic actors increased speed, efficiency, and trust that the contract will be executed as agreed, thus enabling arm's length transactions and payments triggered on receipt of goods. A further application is in the realm of providing more secure and inclusive voting and elections. The danger, of course, is that the contract performs no matter what: this raises questions about who writes them (Quis custodiet ipsos custodies?), how to write-in flexibility to respond to and incorporate external events, and individual's free will in connecting with them.

It is a small step from smart contracts to Decentralized Autonomous Organizations (DAOs) which are similarly executed by code but, unlike smart contracts, may include a potentially unlimited number of participants (Buterin, 2014). DAOs remain largely 
untested and use cases relating to SDGs are hard to find: nevertheless, indicative of the infancy of the technology, one major DAO initiative fell victim to misappropriation of approximately \$80m (Price, 2016), indicating the need for further developmental work. One area where the concept has been developed is in the creation of DLT mediated organisations made of people but where the governance structure is encoded directly into the technical infrastructure stipulating and enabling the rules and procedures of the organisation that every member of the organisation will have to abide by such design propositions may help to eliminate fraud and corruption.

\section{Sharing economy}

The sharing economy has been heralded as one solution to the challenges of sustainability by promoting environmentally sensitive forms of consumption, encouraging different models of ownership and addressing issues such as the underutilisation of assets. However, some scholars recognise a Dark Side (Malhotra and Van Alstyne, 2014), partly for its tendency to reinforce the contemporary unsustainable economic paradigm (Martin, 2016), partly because some providers' business models are argued to be as much about evading regulations as about sharing, partly for spreading precarity throughout the workforce, for middlemen sucking profits out of previously un-monetized interactions (Scholz, 2016) and for being unavailable to disadvantaged groups, those of low socioeconomic status and users from emerging regions (Thebault-Spieker et al., 2015).

DLTs address some of these criticisms by decentralising and disintermediating. Embedding sensors into existing assets, our 'things' can collect and share data. By 
integrating these data into the blockchain, we can keep an immutable ledger of shared transactions without the need for middlemen (Huckle et al., 2016). La' $\mathrm{Zooz}^{13}$ is a decentralized transportation platform owned by the community and utilising vehicles' unused space, enabling people with private cars to share their drive with others travelling the same route: a decentralized Uber.

La'Zooz generates new tokens from 'Proof of Movement' not 'Proof of Work.' As they drive, drivers earn Zooz, passengers pay using Zooz and can also earn Zooz by providing route advice to drivers. La'Zooz offers to provide a ride-sharing service that is based on truer sharing economy principles, rather than monetary incentives (Bheemaiah, 2015). The business model moves from rent extraction to value creation in networks: value is distributed amongst those who created it, offering a greater reward and opportunity for inclusion.

\section{Financial inclusion}

The opportunity for wider financial inclusion is held up as one of the great promises for SDGs of DLTs. Through automation, disintermediation, low cost and security of transfer comes the opportunity for transactions involving low-value units and for remote, disenfranchised, peripheral and marginal communities to connect in new ways either amongst themselves or with activities in the wider world. DLTs allow the almost instantaneous transfer of digital tokens, if not at zero cost then at a significantly cheaper rate than established services. This makes the transfer of small amounts of currency economically viable, enabling new actors to enter the field and new opportunities for e-

\footnotetext{
${ }^{13} \mathrm{http}: / /$ lazooz.net/
} 
commerce (Athey, 2015). It might be anticipated, then, that reductions in the cost of financial transactions through DLTs will result in widening financial inclusion.

One critical factor in enabling greater financial inclusion is identity which, it is argued (Birch, 2014) will underpin future digital transactions and lies at the heart of realising the potential of DLT. The question of what defines identity is challenging, not least because it 'does not lend itself easily to definition nor does it remain unchangeable' (Ajana, 2010, p.5). Identities are made up of multiple attributes: date and place of birth, parents' names, school, criminal record, employment record, biometrics, papers published, etc. These attributes reflect who we are and are configurable depending on whom we need to identify ourselves to and for what purpose.

For most, it is relatively straightforward to assemble authenticated attributes of identity (passport, utility bill, etc.), but approximately $1.8 \mathrm{bn}$ of the world's population have no legally recognised identity (Dahan and Gelb, 2015). The reasons are various, but the consequence is that the 'identityless' exist on the margins of society unable formally to participate in democratic, educative, healthcare and economic activity.

Part of the problem of identitylessness is the extent to which identity has been a centralised phenomenon, something that, to a large extent, is given to people by some authority. The affordances of DLTs offer an alternative approach to building identities from the bottom up, as the gradual accretion of different attributes of identity. This way, an individual's identity is not under the control or the gift of any central authority, nor is it vulnerable to tampering or theft from malicious third parties. Further, individuals are 
able to control which attributes may/may not be made public depending on the authentication need. This is currently an area of intense DLT development including initiatives from ID2020 ${ }^{14}$, BitNation $^{15}$, BlockchainBorderBank ${ }^{16}$, BanQu $^{17}$, and NevTrace ${ }^{18}$.

\section{Conclusion}

In 2013 Nobel Prize-winning economist, Paul Krugman declared that 'Bitcoin is evil.' Others, too, have been critical (Lemieux, 2013; Doguet, 2013; Fox-Brewster, 2015; Welch, 2015; Böhme et al., 2015). Despite these criticisms, DLTs have also been heralded as an incremental innovation with the potential for inducing efficiency gains and ethically empowering business, or disruptive innovations (triggering the emergence of new economic systems), that may prove to be more socially and environmentally responsible (Swan, 2015; Davidson et al., 2016; Walport, 2016).

This paper has explored, through affordance theory, how DLTs might contribute to the sustainability agenda. On the face of it, the potential appears significant. DLTs provide a technical basis for a degree of change that many observers have found exciting. The way we relate to DLTs is not merely a technical matter but strongly relates to the ways in which we configure our social world (Reijers and Coeckelbergh, 2016).

Consequently, we propose the notion of Blockchain for Good as an emergent phenomenon or shared interpretative schema that is being co-constructed by a wide ecosystem of actors as a means of giving direction and catalyzing actions, choices, and

\footnotetext{
${ }^{14}$ http://id2020.org/

$15 \mathrm{https} / / /$ bitnation.co/

${ }^{16} \mathrm{http}: / /$ law.mit.edu/blockchainborderbank

${ }^{17} \mathrm{http}: / /$ www.banquap.com/

${ }^{18} \mathrm{http}: / /$ nevtrace.com/
} 
behaviours (Ranson et al., 1980). Crucially, this approach unlocks the potential for more detailed examinations of the moral and ethical impetus behind blockchain projects.

Within this limited space, we have presented a rather one-sided perspective and are aware that DLTs are not a universal panacea. The notion of Blockchain for Good inevitably raises questions about its counter, 'Blockchain for Bad' and there exists, beyond the scope of this paper, a body of cautionary literature. Analysing cryptocurrencies through the lens of ethical impact, Dierksmeier and Seele (2016) also find detrimental outcomes, such as the facilitation of nefarious consumption. Physicist Stephen Hawking, Elon Musk and, as of 12 November 2016, 8,749 others have signed an open letter counselling against the incautious application of artificial intelligence and DAOs (Russell et al., 2015). DLTs feel no guilt, regret or remorse. This raises questions about who will do the coding. As yet, there is little regulation specific to DLT. Still, might DLTs yet be subsumed by incumbent organizations and authorities as another tool of control and surveillance, or can they really deliver a more democratic, egalitarian, collaborative and sustainable society?

DLTs are still at an early stage of development, and it remains unclear in which direction they will go. The essential premise of technology affordance is that to understand the uses and consequences of technologies, they must be considered in the context of their dynamic interactions between people and organizations (Majchrzak and Markus, 2012), DLTs are a case-in-point. Dozens of crypto-currencies now exist, each optimized for different purposes, each idiosyncratic in terms of its operation, uptake, 
exchange rate and convertibility. Similarly, others are exploring DLT applications that are not currency-oriented. Given this variety, further research is required to understand which type works best in which circumstances and why, as well as the extent to which they can deliver on the sustainability agenda.

\section{References}

Ajana B. 2010. Recombinant identities: Biometrics and narrative bioethics. Journal of Bioethical Inquiry 7: 237-258.

Alejandro J. 2016. Blockchain for good - a beginner's guide. Available at: http://tech.newstatesman.com/guest-opinion/blockchain-for-good-beginners-guide Ali R, Barrdear J, Clews R, Southgate J. 2014. Innovations in payment technologies and the emergence of digital currencies. Bank of England Quarterly Bulletin 54(3): 262-275. Argandoña A. 2003. The New Economy: Ethical issues. Journal of Business Ethics 44: $3-22$.

Aste T. 2016. The Fair Cost of Bitcoin Proof of Work. Available at: https://ssrn.com/abstract $=2801048$

Athey S. 2015. 5 ways digital currencies will change the world. Available at: https://www.weforum.org/agenda/2015/01/5-ways-digital-currencies-will-change-theworld/.

Bateman A. 2015. Tracking the value of traceability. Supply Chain Management Review (November): 8-10.

Benkler Y, Nissenbaum H. 2006. Commons-based peer production and virtue. Journal of Political Philosophy 14: 394-419. 
Bheemaiah K. 2015. Why business schools need to teach about the blockchain. Available at: http://ssrn.com/abstract=2596465.

Birch D. 2014. Identity Is The New Money. London: London Publishing Partnership.

Böhme R, Christin N, Edelman B, Moore T. 2015. Bitcoin: Economics, technology, and governance. The Journal of Economic Perspectives 29: 213-238.

Botsman R, Rogers R. 2010. What's Mine Is Yours: How Collaborative Consumption is Changing the Way We Live. HarperBusiness: London.

Beynon-Davies, P. and Lederman, R., 2017. Making sense of visual management through affordance theory. Production and Planning, 28(2): 142-157.

Boyd, D., 2010. Social networked sites as networked publics: Affordances, dynamics and implications. In: Z. Papacharissi, ed. Networked Self: Identity, Community, and Culture on Social Networking Sites. Routledge: New York; 39-58.

Bradbury D. 2013. Colored Coins Paint Sophisticated Future for Bitcoin. Available at: http://www.coindesk.com/colored-coins-paint-sophisticated-future-for-Bitcoin/.

Buterin V. 2014. DAOs, DACs, DAS and more: An incomplete terminology guide. Available at: https://blog.ethereum.org/2014/05/06/daos-dacs-das-and-more-anincomplete-terminology-guide/

Choy K, Schlagwein, D.2016. Crowdsourcing for a better world: On the relation between IT affordances and donor motivations in charitable crowdsourcing. Information Technology and People 29(1): 221-247.

Ciavola B, Gershenson, J. 2016. Affordance theory for engineering design. Research Engineering Design 27: 251-263. 
Conole G, Dyke M. 2004. What are the affordances of information and communication technologies? ALT-J Research in Learning Technology 12(2): 113-124.

Casalotti A. 2016. Global Carbon Trading on the Blockchain. Bitcoin and Blockchain Leadership Forum. Available at:

http://cptm.org/documents/CFMM_Brief_percent202016.pdf

CPTM. 2016. Commonwealth Partnership for Technology Management (CPTM) Brief on Adaptive Flexibility Approaches to Financial Inclusion in a Digital Age:

Recommendations and Proposals. London: CPTM Smart Partners' Hub.

Dahan M, Gelb A. 2015. The Role of Identification in the Post-2015 Development Agenda. World Bank Working Paper.

Davidson S, De Filippi P, Potts J. 2016. Economics of Blockchain. Available at: http://ssrn.com/abstract=2744751.

Dierksmeier C, Seele P. 2016 Cryptocurrencies and Business Ethics. Journal of Business Ethics 1-14.

Doguet J. 2013. The nature of the form: Legal and regulatory issues surrounding Bitcoin digital currency system. Louisiana Law Review 73(4):1118-1153.

European Central Bank. 2012. Virtual Currency Schemes. Available at: https://www.ecb.europa.eu/pub/.../virtualcurrencyschemes201210en.pdf Fox-Brewster T. 2015. How hackers abused Tor to rob blockchain, steal Bitcoin, target private email and get away with it. Forbes 24 (02):7.

Frankena WK.1973. Ethics. Prentice Hall: Englewood Cliffs. 
Faraj J, Jarvenpaa S, Majchrzak A. 2011. Knowledge collaboration in online communities. Organization Science 22(5): 1224-1239.

Gaver W. 1991. Technology Affordances. ACM: New Orleans, Lousiana, New York: $79-84$.

Geels FW. 2005. Technological Transitions and System Innovations: A Co-

Evolutionary and Socio-Technical Analysis. Edward Elgar Publishing: Cheltenham UK:

Gibson JJ. 1978. The ecological approach to the visual perception of pictures. Leonardo 11: $227-235$.

Greenspan G. 2015. MultiChain Private Blockchain - White Paper. Available at: http://www.multichain.com/white-paper/: Multichain

Halford R. 2014. Gridcoin - Crypto-Currency using Berkeley Open Infrastructure Network Computing Grid as a Proof Of Work. Available at: http://www.gridcoin.us/images/gridcoin-white-paper.pdf

Helbing D. 2013. Economics 2.0: The natural step towards a self-regulating, participatory market society. Evolutionary and Institutional Economics Review 10: 341.

Helbing D. 2014. Qualified Money-A Better Financial System for the Future. Available at: 2526022 .

Huckle S, Bhattacharya R, White M, Beloff N. 2016. Internet of things, blockchain and shared economy applications. Procedia Computer Science 98: 461-466.

Jovanovic B, Rousseau PL. 2005. General purpose technologies. Handbook of Economic Growth 1: 1181-1224. 
Kewell B. 2007. Linking risk and reputation: A research agenda and methodological analysis.' Risk Management: An International Journal 9(4): 238-254.

Kranzberg M. 1986. Technology and History: 'Kranzberg's Laws.' Technology and Culture 27: 544-560.

Krugman PR. 2013. Bitcoin is evil. Available at:

http://krugman.blogs.nytimes.com/2013/12/28/Bitcoin-is-evil/?_r=1: New York Times.

Lee E. 2005. The ethics of innovation: P2P software developers and designing substantial noninfringing uses under the Sony Doctrine. Journal of Business Ethics 62:147-162.

Lemieux P. 2013. Who is Satoshi Nakamoto? Regulation (Fall):14-15.

Lankton N, McKnight D, Tripp J. 2015. Technology, humanness, and trust: rethinking trust in technology. Journal of the Association for Information Systems 16(10): 880-918.

Maier J, Fadel G. 2009. Affordance-based design: A relational theory of design. Research Design Engineering 20: 13-27.

Majchrzak A, Markus L. 2012. Technology Affordances and Constraint Theory of MIS. Thousand Oaks: CA. Sage Publishing.

Malhotra A, Van Alstyne M. 2014. The dark side of the sharing economy... and how to lighten it. Communications of the ACM 57: 24-27.

Martin CJ. 2016. The sharing economy: A pathway to sustainability or a nightmarish form of neoliberal capitalism? Ecological Economics 121: 149-159.

Martin, K.E, Freeman, R.E. 2004. The separation of technology and ethics in Business Ethics. Journal of Business Ethics 53: 353-364. 
Mattila J. 2016. The Blockchain Phenomenon: The Disruptive Potential of Distributed Consensus Architectures. Available at: http://brie.berkeley.edu/BRIE/:

Berkeley Roundtable on the International Economy (BRIE), University of California, Berkeley.

McWaters R, Galaski R, Chaterjee S. 2016. The Future of Financial Infrastructure: An Ambitious Look at How Blockchain can Reshape Financial Services. World Economic Forum Available at: https://www.weforum.org/reports/the-future-of-financialinfrastructure-an-ambitious-look-at-how-blockchain-can-reshape-financial-services/ Nakamoto S. 2008. Bitcoin: A peer-to-peer electronic cash system. Consulted, 1, 28. Ng I. 2013. Value and Worth: Creating New Markets In The Digital Economy. Innovorsa: Cambridge.

ODI. 2016. Applying Blockchain Technology in Global Data Infrastructure. Available at: http://theodi.org/technical-report-blockchain-technology-in-global-datainfrastructure: Open Data Institute Pea RD. 1993. Practices for distributed intelligence and designs for education. In Salomon G (ed) Distributed Cognitions: Psychological and Educational Considerations. Cambridge University Press: Cambridge, UK; 47-87.

Potts J, Davidson S, De Filippi P. 2016. Disrupting governance: The new institutional economics of Distributed Ledger Technology. Available at: http://ssrn.com/abstract=1295507

Price R. 2016. Digital currency Ethereum is cratering amid claims of a $\$ 50$ million hack. Business Insider (17 June) Available at: http://uk.businessinsider.com/daohacked-ethereum-crashing-in-value-tens-of-millions-allegedly-stolen-2016-6 
Ranson S, Hinings B, Greenwood R. 1980. The structuring of organizational structures. Administrative Science Quarterly 25: 1-17.

Reber D, Feuerstein S. 2014. Bitcoins-hype or real alternative? Internet Economics VIII (81).

Reijers W, Coeckelbergh, M. 2016. The blockchain as a narrative technology:

Investigating the social ontology and normative configurations of cryptocurrencies.

Philosophy of Technology (October):1-28.

Rizzo P. 2016. Sweden tests blockchain smart contracts for Land Registry. CoinDesk June 16 .

Russell SV, Dewey D, Tegmark M. 2015. Research priorities for robust and beneficial artificial intelligence: An open letter. Association for the Advancement of Artificial Intelligence.

Scholz T. 2016. Platform Cooperativism: Challenging the Corporate Sharing Economy. New York. Available at : www.rosalux-nyc.org, Rosa Luxemburg Stiftung

Schumpeter JA. 1934. The Theory of Economic Development: An Inquiry into Profits, Capital, Credit, Interest and the Business Cycle. London, UK: Oxford University Press.

Seidel S, Recker J, Vom Brocke J. 2013. Sensemaking and sustainable practicing: Functional affordances of information systems in green transformations. MIS Quarterly 37: $1275-1299$.

Shin L. 2016. Republic of Georgia to develop blockchain Land Registry system. Forbes, 21 April.

Smith JW. 1948. Intrinsic and extrinsic good. Ethics 58: 195-208. 
Swan M. 2015. Blockchain: Blueprint for a New Economy. O'Reilly Media, Inc.:

Beijing, Cambrdige, Farnham, Koln, Sebastopol, Tokyo.

Taddeo M, Vaccaro A. 2011. Analyzing peer-to-peer technology using information ethics. Information Society 27: 105-112.

Taghiyeva M, Mellish B, Ta'eed O. 2016. Currency of Intangible Non-Financial Value. Available at: https://github.com/seratio/whitepaper: IoV Blockchain Alliance for Good (www.bisgit.org)

Thebault-Spieker J, Terveen LG, Hecht B. 2015. Avoiding the South Side and the Suburbs: The Geography of Mobile Crowdsourcing Markets. Proceedings of the 18th ACM Conference on Computer Supported Cooperative Work and Social Computing; $265-275$.

UN. 2015. Transforming our world: The 2030 Agenda for Sustainable Development. Available at: https://sustainabledevelopment.un.org/post2015/transformingourworld. Volkoff O, Strong DM. 2013. Critical realism and affordances: Theorizing ITassociated organizational change processes. MIS Quarterly 37: 819-834.

Xenakis I, Arnellos A. 2013. The relation between interaction aesthetics and affordances. Design Studies, 34 (1): 57-73.

Walport. 2016. Distributed Ledger Technology: Beyond Blockchain. Government Office for Science. Available at: https://www.gov.uk/government/publications/distributed-ledger-technology-blackettreview

WCED. 1987. Our Common Future. World Commission on Environment and Development. Oxford University Press: Oxford, UK. 
Welch A. 2015. The Bitcoin blockchain as financial market infrastructure: A consideration of operational risk. Legislation and Public Policy 8: 837-893.

Withagen R, Chemero, A. 2012. Affordances and classification: On the significance of a sidebar in James Gibson's last book. Philosophical Technology 25(4): 521-537.

Wright A, De Filippi P.2015. Decentralized Blockchain Technology and the Rise of Lex Cryptographia. Available at:

https://papers.ssrn.com/sol3/papers.cfm?abstract_id=2580664

Zuberi M, Levin R. 2016. Schumpeter's Revenge: The gale of creative destruction. Banking and Financial Services Policy Report 35(5):1-8.

Zammuto R, Griffith T, Majchrak A, Dougherty D, Faraj S. 2007. Information technology and the changing fabric of organization. Organizational Science 18(5): 749762.

\section{Biographical Notes}

Beth Kewell is a Research Fellow at Surrey University Business School's Centre for the Digital Economy (CoDE), where she specialises in interpretative research, positioned at the boundary between innovation management, Science and Technology Studies (STS), and risk analysis.

Correspondence to: Surrey Centre for the Digital Economy, University of Surrey, Surrey GU2 7XH, UK.

Email: e.kewell@surrey.ac.uk

Richard Adams is a Senior Research Fellow at Surrey University Business School's Centre for the Digital Economy (CoDE). His research interests lie at the intersection of (responsible) innovation, digital disruption, and sustainability and business models.

Correspondence to: Surrey Centre for the Digital Economy, University of Surrey, Surrey GU2 7XH, UK.

Email: r.adams@surrey.ac.uk 
Glenn Parry is Professor of Strategy and Operations Management at Bristol Business School, University of the West of England. He is primarily interested in what 'Good' means for an organisation, exploring value as a measurement of 'goodness'. He uses business models as a framework to understand value co-creation between provider and client in context.

Correspondence to: Faculty of Business and Law, UWE Frenchay Campus, Coldharbour Lane, Bristol, BS16 1QY, UK.

Email: Glenn.Parry@uwe.ac.uk 